\title{
El caso Julian Assange. El derecho a la autobiografía no autorizada*
}

\author{
Oscar GóMEZ \\ GESC
}

(Abstracts y palabras clave al final del artículo)

Enviado: 14 de agosto de 2015

Aceptado: 18 de agosto de 2015

Cuando eres un hacker, vives [...] de otra manera con respecto a la norma, no solo por el uso de un seudónimo o un nombre de guerra, sino por el uso de una serie de máscaras dentro de otras máscaras hasta que finalmente, si eres bueno, tu actividad es tu identidad y tu conocimiento es tu rostro.

Julian Assange, Autobiografía no autorizada.

El estallido del fenómeno WikiLeaks produjo, en el mismo espacio temporal y mediático, un exponencial aumento de información en torno a la figura de Julian Assange, como ya saben, el fundador del portal responsable de la mayor filtración de documentos (presumiblemente secretos) de la historia. Los medios lo convirtieron rápidamente en el nuevo icono de la libertad de expresión, en el estandarte de una revolución a nivel mundial que acababa de comenzar, en el epítome de la transparencia absoluta. Si bien es verdad que la figura de Assange es de alguna manera, como hemos tenido ocasión de indicar en otro lugar ${ }^{1}$, la imagen más representativa (si el logo de WikiLeaks nos lo permite) de un fenómeno prácticamente anicónico, que llama precisamente la atención por la cantidad de información en bruto con la

\footnotetext{
* Este artículo se enmarca dentro del Proyecto de Investigación I+D "El fenómeno WikiLeaks en España: un análisis semiótico y mediológico" (Ref.:CSO2011-23315). Me gustaría expresar aquí un especial agradecimiento a Tarcisio Lancioni, director del Centro di Semiotica e Teoria dell'Immagine "Omar Calabrese", y a sus miembros Maria Cristina Addis, Stefano Jacoviello y Giacomo Tagliani, que tuvieron a bien recibirme durante algunos meses y que han sabido enriquecer este artículo con numerosos comentarios. También a Jorge Lozano, director del GESC, y a Rayco González, Marcello Serra y Gérald Mazzalovo. Con ellos he podido consultar y discutir, en el marco del seminario permanente que el grupo organizó en torno a la investigación, muchos de los temas que aquí se tratan. Agradezco enormemente su tiempo, su escucha, y su dedicación.

1 Véase Francescutti et al. 2012.
} 
que la que proveyó a los periódicos, y que esta imagen condensaba en gran medida el ethos y el pathos de todo WikiLeaks, también es verdad que el relato que se generó en torno a su persona, su vida y sus acciones, en muchas ocasiones ha ido en paralelo al de su organización. Podemos hablar de dos relatos diferentes, con recorridos narrativos igualmente diferentes.

En una dinámica acorde con el propio funcionamiento de los media, Assange se vio sometido a un proceso de celebrificación ${ }^{2}$ que certificaba su liderazgo en lo que se dio en llamar como la Primera Guerra Mundial de la Información y que permitía "personalizar" un acontecimiento mediático como WikiLeaks seleccionando al personaje necesario para construir el espectáculo periodístico que las revelaciones impulsaron ${ }^{3}$.

En este artículo, nuestra intención será abordar la construcción de sentido del personaje de Assange, prestando atención a lo que se ha dicho sobre él, al aparato intertextual construido alrededor de sus acciones, su pensamiento y su proyecto. También se abordarán algunos de los problemas que plantea su autobiografía no autorizada, para proponer una definición de nuestro objeto de análisis y comprobar eventualmente lo que esta nos puede sugerir sobre la construcción de ídolos e iconos en una semiosfera mediática que está plagada de relatos sobre personas cuya vida y acciones se eligen para pasar a formar parte de nuestra memoria cultural. Son sujetos que han obtenido, en palabras de Lotman, el derecho a una biografía, que aquí entenderemos como la configuración de prácticas discursivas que tienden a singularizar a unos individuos para diferenciarlos de la colectividad.

\section{EL DERECHO A LA BIOGRAFÍA DE ASSANGE}

Siguiendo a Lotman (1992) en su atento análisis sobre el tema ${ }^{4}$, desde que nacemos, se nos presenta de la misma manera que la lengua natal, toda una serie de roles, un corpus de normas y en definitiva, toda una semiótica de lo social que se nos presenta como "condición de juego" y en la que al individuo se le da la opción de elegir dentro de un cierto repertorio. Una vez que ha hecho su elección, se moverá en lo que su código cultural defina como "conducta correcta". Lotman se pregunta: ¿qué tienen en común la biografía de un santo medieval, formada en torno a un

\footnotetext{
2 Cfr Rojek 2001. El término “celebrification” hace referencia al proceso mediático mediante el cual un individuo se convierte en celebrity. Se trata al mismo tiempo de un marco de referencia (en el sentido goffmaniano del término) que, definido por los media, configura un cierto tipo de relación social entre la celebrity y su audiencia, al tiempo que da instrucciones para una determinada lectura. El concepto de celebrity, cuyo abordaje exhaustivo excedería sin duda los objetivos de este análisis, será definido, en estas páginas, siguiendo a Rojek y dejando a un lado las posibles implicaciones éticas, morales y estéticas, como aquel sujeto de identidad mediatizada cuyos actos producen un cierto impacto en la conciencia pública y cultural, diferenciándose de este modo del resto de la gente.

${ }^{3}$ Se recomienda la lectura de algunas de las publicaciones que han surgido al calor de nuestra investigación sobre WikiLeaks, especialmente Lozano y Díaz 2013, Lozano 2014 y Albergamo 2014.

${ }^{4} \mathrm{El}$ artículo, intitulado "La biografía literaria en el contexto histórico cultural (sobre la correlación tipológica entre el texto y la personalidad del autor)" (1992) fue incluido en el volumen La Semiosfera II. Semiótica de la cultura, del texto, de la conducta y del espacio (1998).
} 
repertorio de tópicos y orientada hacia el cumplimiento exacto de la norma, y una biografía de la Edad Moderna, orientada hacia el incumplimiento de la norma, y que se centra en los rasgos inigualables de un determinado individuo? A lo que contesta:

Entre ellas hay algo en común: de toda la masa de personas cuya vida y actos no se hacen objeto de descripción, se escoge alguien cuyo nombre y actos se conservan para los descendientes.[...] En ambos casos el hombre realiza no una norma rutinaria, media, de conducta, para la época y socium dados, sino una norma difícil e inusual, "extraña" para los otros y que exige de él grandísimos esfuerzos (Lotman 1998: 153)

Es de esta manera como puede explicarse el nacimiento de las tipologías del héroe, el bandido, el mago, el bohemio etc., que reciben una norma especial y un derecho a una excepcionalidad en la conducta desde el punto de vista de lo que los códigos culturales consideran como correcto. Podrán ser valoradas positiva o negativamente, pero ya han obtenido el derecho a la biografía y con ello, a entrar en la memoria de una determinada cultura. Una persona con biografia surge por tanto de la relación que establece con la norma que una determinada cultura implanta.

Si aplicamos esto a Assange comprobamos cómo su actitud ante la norma, entre la rebelión y la creación de una norma nueva fundamentada en el cambio tecnológico y en la aplicación de muchos de los presupuestos de la ética hacker (o nética según Himanen), ha producido una gran cantidad de relatos que dificultan el establecimiento de una sanción más o menos definitiva en torno a su persona. En cualquier caso, sí que puede asegurarse que a lo largo de su trayectoria, y en función de quién hable (el punto de vista), Assange ha adoptado una serie de roles temáticos diversos. Así, desde el estallido de Cablegate, Assange se convirtió en un héroe, equiparado en su dimensión mítica con Prometeo o con Robin Hood, que acaparó portadas en todo el mundo. La revista Time lo nominó a hombre del año y la versión italiana de Rolling Stone, por poner un ejemplo, lo convirtió en rockstar del año (fig. 1). Al mismo tiempo, en los Estados Unidos se le acusa de terrorista informático (villano) y hay quien pide su cabeza ${ }^{5}$. Otros defienden que es un traidor, cuando se difundió la noticia de que las fuentes de las filtraciones iban a ser desveladas.

5 Jeffrey T. Kuhner: “Assasinating Assange”, The Washington Times, 2 de diciembre de 2010. 

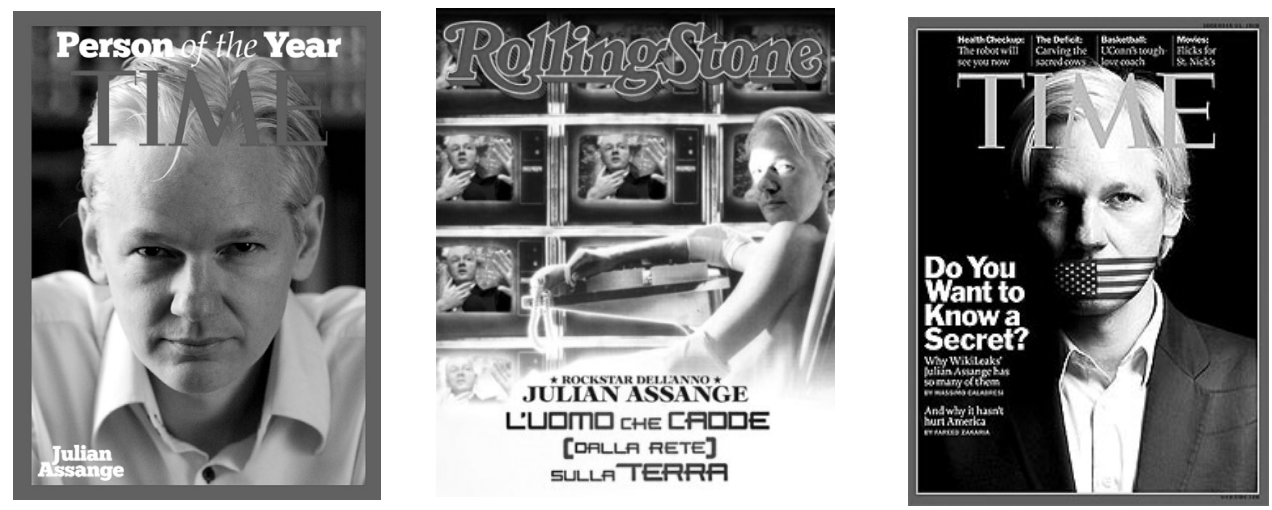

Fig. 1. Julian Assange elegido "Personaje del año" por la revista Time. La "rockstar" del año para la versión italiana de Rolling Stone. Portada en la revista Time. Todas las imágenes corresponden a diciembre de 2010.

También cumplirá el rol de fugitivo, al que la justicia busca por haber violado supuestamente a dos mujeres. Domscheit-Berg, antiguo colaborador de Wikileaks, llega a denominarlo dictador egomaníaco (Domscheit-Berg 2011: 182-192). El propio Assange se declara víctima de un complot (mártir), al tiempo que asegura que seguirá luchando por sus ideales, etc. En los últimos años, que van desde el arresto domiciliario en el Reino Unido al encierro en la Embajada de Ecuador en Londres, hemos visto como Assange se convertía, entre otras cosas, en showrunner de un programa de entrevistas para la televisión rusa, ejercía de activista pro derechos humanos en lo respectivo al caso Manning, se postulaba de manera un tanto excéntrica 6 a las elecciones del Senado en Australia obteniendo resultados desastrosos, se definía como periodista, producía documentales, se convertía en holograma ${ }^{7}$ para poder asistir a un congreso sobre tecnología en EE.UU, y finalmente, en marca ${ }^{8}$, quizás la culminación de un proceso de iconización que comenzó hace poco más de cinco años pero que aún debería confirmar su eficacia.

Lo interesante de todos estos roles, entendidos como formulaciones actanciales de determinados recorridos temáticos (cfr. Greimas 1979: 344), es que más que anularse, conviven en tensión en el seno de la semiofera mediática y nos muestran diferentes niveles narrativos cuyos propósitos se presentan de manera heterogénea. En esta línea, si enmarcásemos el relato en el esquema narrativo básico, veríamos cómo esta aparente contradicción puede explicarse en términos de la sanción que un destinador quiere depositar sobre Assange. Greimas (1979: 346-347) distinguirá en su diccionario entre sanciones pragmáticas y sanciones cognoscitivas. Mientras que la sanción pragmática es un juicio sobre la conformidad del programa narrativo del sujeto (Assange) en relación a un sistema axiológico dado, la sanción cognoscitiva es un juicio epistémico sobre el "ser" (sobre los enunciados de estado). En el nivel

\footnotetext{
6 Se recomienda ver el videoclip que protagonizó para promocionar su candidatura. Puede verse en este link: https://www.youtube.com/watch?v=dc_hbX2DxJQ.

7 "Assange se cuela en EE.UU como un holograma 3D", abc.es, 30 de septiembre de 2014 (http://www.abc.es/internacional/20140930/abci-assange-cuela-como-holograma-201409301237.html)

8 "The Branding of Julian Assange" (Vanessa Friedman, The New York Times, 22 de octubre de 2014)
} 
pragmático encontraríamos la "recompensa" o el "castigo", mientras que en el cognoscitivo nos encontraríamos con el "elogio" o la "censura". De esta manera, podríamos esbozar una suerte de tipología, fundamentada en los diferentes enunciados "sancionadores" vertidos sobre un sujeto, que podría ser útil para definir de qué manera un sujeto con biografía se inscribe en la memoria cultural. Memoria que, por otro lado, como indicó Lotman, funciona fijando tanto las normas, como las violaciones de estas normas.

En cualquier caso, en toda esta confusión motivada por la profusión de relatos sobre la persona de Assange, un texto, publicado por Canongate Books en 2011, quiso aportar el propio punto de vista de nuestro objeto de análisis. En toda biografía hay un sujeto sobre el que se escribe, un lector y un tercer actor, el que la escribe, al que no le hemos prestado demasiada atención hasta ahora, pero que cobra en lo que sigue una especial relevancia.

\section{LA AUTOBIOGRAFÍA NO AUTORIZADA DE JULIAN ASSANGE}

Este trabajo fue elaborado durante el período de arresto domiciliario en el Reino Unido (2010) y quiso ser, en palabras del propio Assange, "uno de los documentos unificadores de nuestra generación". No obstante, cuando el primer borrador de la obra llegó a sus manos, lo consideró demasiado personal (¿existen autobiografías impersonales?), y declaró que toda autobiografía "es un acto de prostitución", solicitando que el libro no viese la luz. Sin embargo, la editorial, que había pagado una cuantiosa suma de dinero a Assange (que este, a su vez, ya se había gastado en abogados), decidió publicarlo finalmente en octubre de 2011. Así justifican su elección en las páginas introductorias:

No estamos de acuerdo con la evaluación de Julian sobre el libro. Creemos que explica tanto el hombre como su obra, y subraya su compromiso con la verdad. Julian siempre afirmó que el libro estaba bien escrito; estamos de acuerdo, y esto también nos animó a poner el libro a disposición de los lectores. [...] Lo que sigue es el primer borrador no autorizado. Es apasionado, provocativo y obstinado, como su autor. Se cumple la promesa de la propuesta original y estamos orgullosos de publicarlo (traducción nuestra).

¿Qué razones pudieron llevar a Assange a no autorizar su propia autobiografía? Si seguimos a Lejeune, en el texto se cumplen todas las premisas que llevarían a este relato a cumplir con el pacto autobiográfico. Por un lado, tenemos un relato "retrospectivo en prosa que una persona real hace de su propia existencia, poniendo énfasis en su vida individual y, en particular, en la historia de su personalidad" (Lejeune 1975: 50). Además, se cumpliría la identificación entre autor, narrador y personaje principal que se requiere para diferenciar el autobiográfico de otros relatos biográficos. Generalmente, la identidad entre el narrador y el personaje principal queda asumida por el uso de la primera persona, el "yo", en lo que Genette llamará narración autodiegética. Ya desde el primer párrafo, nos encontramos con lo siguiente: 
Me considero afortunado por haber nacido entre gente curiosa que llenaba el aire con preguntas. Un día conocería a mis enemigos y me odiarían por desear la verdad. Uno casi podría olvidar su propio nombre entre tantos insultos. Sin embargo, sé bastante bien quien soy y esperaba poder contárselo yo mismo. Mi nombre es Julian Assange (Assange 2011: 8, traducción nuestra).

La identificación queda establecida, como se ve, de manera evidente. Y en efecto, a lo largo de todas las páginas del libro, este autor-narrador- personaje nos cuenta en primera persona su infancia y adolescencia en Melbourne (descrita como la infancia de un Tom Sawyer, con numerosas aventuras, conquistando siempre el peligro, etc.), el origen de su apellido ${ }^{9}$, los problemas con su padastro, perteneciente una secta conocida como "The Family", de quien siempre estaban huyendo a lo largo y ancho de la geografía australiana, la adquisición de su primer ordenador y las primeras escrituras de código, la llegada de internet y con ello la apertura de todo un mundo de posibilidades no solo para él mismo, sino "para toda la humanidad". También se nos habla de sus comienzos como hacker, de su apodo, Mendax, adoptado tras la lectura de Horacio y que podría traducirse como "deliciosamente engañoso", del nacimiento de los cyperphunks, "code breakers" según la denominación de Levy (1984) y su afiliación a los International subsersives, etc.

Mas adelante, siempre en primera persona, se nos relatarán sus primeros problemas con la justicia, su paso por la universidad, donde estudiando física cuántica y matemáticas comienza a interesarse, de manera casi obsesiva, dirá, por el problema de la información, a preguntarse cómo circula entre las personas y la sociedad y a razonar sobre las posibilidades que un nuevo tipo información tendría para generar un cierto tipo de cambio social. Además, ahonda en sus reflexiones sobre el poder de los medios y las grandes corporaciones mediáticas y el flaco favor que hacen a un sentido de la justicia verdaderamente justo. Finalmente la creación de WikiLeaks, la búsqueda de fondos, el proceso de elaboración de Collateral Murder, su estancia en Suecia, su relación con dos mujeres que acabarían denunciándolo por violación y finalmente todo el proceso de preparación de lo que se denominaría a nivel mundial como el Cablegate.

Además del relato de una vida, en el texto se aprecian numerosas operaciones destinadas a construir un rol heroico, en el sentido proppiano del término, como aquella figura destinada a restablecer un orden social que se encuentra perturbado (Greimas 1970: 273-274). En el primer capítulo del libro, en el que se nos narran los días en prisión previos a su escritura, Assange nos cuenta las duras e injustas condiciones a las que está sometido, al tiempo que quiere compararse con otras figuras que él considera heroicas como Daniel Ellsberg, Oscar Wilde (curiosamente,

\footnotetext{
${ }^{9}$ Assange adopta su apellido de Bret Assange, el segundo marido de su madre tras el abandono del padre biológico. En el texto, Assange explica que su apellido no es de ascendencia francesa, sino que viene del taiwanés Ah-sang. Su tatarabuelo, George Ah Sang, fue un pirata (sic) que se estableció en Australia y el que, para evitar los problemas de discriminación que había época contra los chinos, y en parte también con el objetivo de dejar atrás su pasado pirata, se inscribió en el Registro como Assange para pasar un poco más desapercibido.
} 
Assange se aloja en la misma celda) o Aleksandr Solzhenitsyn, a los que define como modelos que le inspiran una determinada lucha por la libertad de expresión y con los que establece una cierta "línea de sucesión" en una clara manifestación de cultura textualizada. Al mismo tiempo, se define nítidamente un programa narrativo en el que "la verdad" se constituye como objeto de valor que Assange tratará de obtener por todos los medios. Dejemos que sea el propio Assange el que nos explique qué es lo que entiende por "verdad":

Durante mi carrera, hasta ahora, cuando hablo de la necesidad de una verdad, estoy hablando, muy a menudo, sobre la verdad en relación a la muerte de miles de personas. $\mathrm{O}$ estoy hablando de fraudes, torturas, corrupciones, que destruyeron la vida de la gente (Assange 2011: 47, traducción nuestra).

En definitiva, nos encontramos frente a un texto que aporta una nueva aproximación a Assange, a su proyecto ético, su personalidad. Un texto que, como en la gran mayoría de relatos autobiográficos, construye un sujeto equilibrado, responsable. En este orden de cosas, a primera vista, lo primero que llama la atención es el hecho de que se trate de una autobiografía no autorizada, es decir, sin autor, o más concretamente, en la que el autor quiere deshacerse de la responsabilidad de serlo. El problema enunciativo que se nos presenta, en un principio, podría ser el que se establece con un "yo" que renuncia a sí mismo, que no se reconoce como un "yo" y por lo tanto reniega de él. Es el problema del nombre propio. Recordemos con Foucault (1969: 329-360) que un nombre propio no debería considerarse solo como un elemento del discurso sino como aquello que garantizaría un "modo de ser" al discurso, y que ejerce, por tanto, una relación con respecto "al" discurso, y no solo dentro de él. Es decir, que el vínculo que se establece entre el nombre propio con el individuo nombrado y el vínculo del nombre de autor con lo que nombra no es isomorfo y no funciona tampoco de la misma manera. El autor, más que un nombre propio, vendría a ser más una función del texto. Para Lejeune, por su parte, el nombre propio sería el lugar "donde persona y discurso se articulan antes incluso de articularse en la primera persona" (Lejeune 1975: 79). Por lo tanto, en el caso que nos ocupa, este "yo" no podría nunca pertenecer al anonimato porque se encuentra reenviando a un nombre propio, Assange, del que se narran unos hechos que coinciden en un espacio extratextual con el "espacio biográfico" que se ha constituido, en tantos lugares, en torno a su persona. Una identidad es o no es, no hay gradación posible y "resulta imposible que la vocación autobiográfica y la pasión de anonimato coexistan en un mismo ser" (ibid: 72). Al mismo tiempo:

En los textos impresos toda la enunciación está a cargo de una persona que tiene por costumbre colocar su nombre en la portada del libro y en la página del título, encima o debajo del título de la obra. En ese nombre se resume toda la existencia de lo que llamamos el autor: única señal en el texto de una realidad extratextual indudable, que envía a una persona real, la cual exige de esa manera que se le atribuya, en ultima instancia, la responsabilidad de la enunciación de todo el texto escrito (ibid: 60). 
La responsabilidad del texto, por tanto, descansará finalmente, muy a pesar de su desautorización, en la misma figura de Assange, cuyo retrato y nombre encontramos en la portada del libro. Además, también aparece como poseedor de los derechos, pero esto ya sería, quizás, otra cuestión (fig. 2). Resulta interesante constatar la isografía existente entre esta imagen y la que hemos visto en fig.1 en la que Assange aparece amordazado por la bandera de los Estados Unidos. En la portada de la autobiografía, en cambio, es el propio Assange el que se silencia, configurándose curiosamente como su propio oponente.

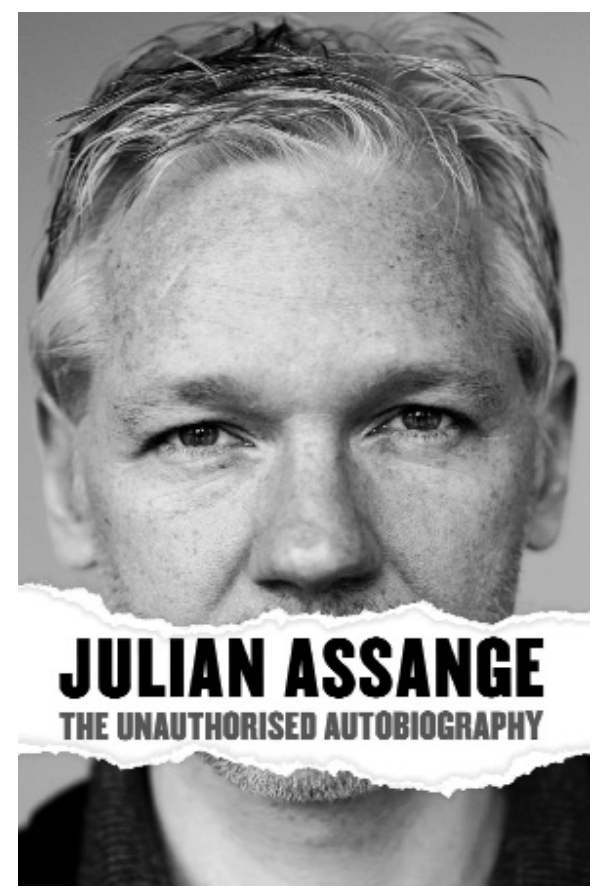

Fig. 2. Imagen de portada del libro.

Por otro lado, existe aún un problema por resolver. ¿Quién escribe verdaderamente el libro? En las páginas introductorias, los editores afirman que el texto surge tras más de cincuenta horas de entrevistas que un ghost writer de identidad desconocida mantuvo con Assange. El recurso a este tipo de figura, que aquí vamos a llamar por comodidad "el redactor" no es algo nuevo y forma parte de una cierta tradición etnológica destinada a dar voz, tal y como indica Lejeune (1975: 313-414), a los que no escriben. Esta figura del redactor tendría todas las funciones de estructuración, comunicación con el exterior y con el establecimiento de un determinado pacto con el lector en términos enunciativos. Es la instancia enunciadora. Se encarga de estructurar la memoria de su modelo, en este caso Assange que, curiosamente, se limitaría en este proceso a ser una fuente, como WikiLeaks. En cualquier caso, este "redactor" se establece como la figura que media entre la memoria de Assange y el punto de vista instaurado en el libro. 
Tenemos por tanto que, ante un extenso material grabado, el relato de Assange, este redactor transforma el testimonio oral en escrito, lo somete a las leyes de la escritura, al mismo tiempo que lo estiliza, dotándolo de un tono literario. Crea un orden del discurso, distribuye el contenido en capítulos (determinados tanto por el propio orden original de la entrevista como por las expectativas del enunciatario) y transforma la entrevista (diálogo) en monólogo. En definitiva, somete al testimonio de Assange a todo un proceso de transformación destinado a la construcción discursiva de un sujeto que debería verse como verdadero, como auténtico, con la construcción de un cierto "efecto de realidad". Esto hace que, realmente, no nos encontremos ante una autobiografía en sentido estricto. En cualquier caso, sería un texto con una autoría compartida, más vinculado al narrador homodiegético, quizás a la "ficción autobiográfica", aunque nuestra hipótesis es distinta, y con esto nos gustaría terminar.

Puede que haya quien piense que las razones que llevaron a Assange a renunciar a su autobiografía tengan que ver con el simple reclamo publicitario, o con aquel problema que planteó Morin relacionado con la incapacidad de un autor de relacionarse con su obra en los tiempos actuales (1962: 42-44), o con haber reflexionado sobre las condiciones de producción reinantes, lo que le llevaría a querer efectuar una crítica sobre el funcionamiento de los medios de producción de información, sirviéndose al mismo tiempo de su función organizadora de contenidos (Benjamin 1934). Puede que haya algo de todo esto que, en cualquier caso, coincide con numerosas consideraciones del ámbito hacker ${ }^{10}$ en un plano axiológico. Sin embargo, de cara a una definición de la figura de Assange, creemos que hay algo más. Una autobiografia, al fin y al cabo, como cualquier relato, establece un contrato con el lector que define unas condiciones de lectura, y genera una serie de expectativas. En este sentido, Assange, figura siempre esquiva, se mantiene fiel a lo que se podría esperar sobre él en un nivel extratextual, y cumpliría en esta obra con una de las principales características de su modus operandi. Tal como nos indica en el libro, en lo que parece un claro homenaje a Oscar Wilde ${ }^{11}$, y quizás dejando voluntariamente alguna pista: "Me gustaba esta idea de esconderme tras un nombre falso, mintiendo sobre quién era o dónde estaba [...] podría hablar con mayor verdad sobre mi verdadera identidad" (Assange 2011: 36, traducción nuestra).

Esto es lo que su no autorización, creemos, quiere significar. Por un lado, constituye un acto de justicia y honestidad para el redactor que escribe pero que no tiene derecho ni a autoría ni a biografía. Hay que tener en cuenta que en un amplísimo porcentaje de autobiografías interviene esta figura del redactor, muchas veces acreditado, mientras que en tantas otras ocasiones, quizás en la mayoría, se trata de una figura invisible, disimulada. Se convierte así la autobiografía en un género-simulacro que crea un pacto con el destinatario que este, sin demasiadas preguntas, acepta. En este sentido, la no autorización de Assange sirve para hacer visible una figura que nadie se habría cuestionado y, en términos de la instancia enunciadora, sirve para establecer un discurso entre la denuncia y la renuncia que tanto caracterizaría su habitual producción discursiva. Esta renuncia y esta

\footnotetext{
10 Para profundizar en la temática, se recomienda acudir a Levy 1984 y Sterling 1992.

11 "Man is least himself when he talks in his own person. Give him a mask, and he will tell you the truth". Con esta cita comienza el libro Underground (Dreyfus, Assange 2011), un intensivo análisis periodístico sobre los orígenes del movimiento hacker en Australia en el que Assange colaboró como asesor.
} 
denuncia, un acto de cancelación perteneciente al ámbito de una cierta iconoclasia, serían los elementos que precisamente colocarían a Assange como autor de la obra, como artífice de todo el dispositivo discursivo (y enunciativo) que acabamos de comentar.

Por último, resulta interesante constatar cómo es en este infinito juego de máscaras donde la figura de Assange encontraría su más profunda significación: en la tensión constante entre el desvelamiento y el ocultamiento. En efecto, es posible reconocer en este relato autobiográfico tanto la figura de Assange (Mendax, el deliciosamente engañoso, el "code breaker") como el simulacro que el propio Assange quiere ofrecernos de sí mismo. En este acto de escribirse quedaría patente uno de los rasgos que, tal como nos enseñó Louis Marin (1999) caracterizarían al relato autobiográfico en términos enunciativos: se habla de un "yo" que en realidad es otro "yo". Como en un retrato ${ }^{12}$, un relato autobiográfico nos presenta, en primera instancia, la proyección de un doble. Un acto de presentarse representándose. Una mirada en el espejo, la imagen que sólo puede verse y que puede no tocarse: un eidolon, una imagen engañosa cuya falsedad está plagada de sentido.

\section{BIBLIOGRAFÍA}

Albergamo, Maria, ed., (2014), La transparencia engaña, Biblioteca Nueva, Madrid.

AssAnge, Julian (2011), Julian Assange. The unauthorised autobiography, Canongate, Edinburgh.

Benjamin, Walter (1934), El autor como productor, Casimiro, Madrid 2015.

Domscheit-Berg, Daniel (2011), Inside WikiLeaks. My time with Julian Assange at the most dangerous website, Crown Publishers, New York.

Dreyfus, Suelette; AsSANGE Julian (2011), Underground. Barcelona, Seix Barral.

FouCAult, Michel (1969), “¿Qué es un autor?”, en Entre filosofía y literatura (Obras esenciales, vol.1), Paidós, Barcelona 1999.

Francescutti, Pablo; Serra, Marcello; Gómez, Oscar y Magallón, Raúl (2012), "El fenómeno WikiLeaks. Entre la Teoría de la Información y la comunicación estratégica" en Revista de Occidente nos374-375.

Greimas, Algirdas J. (1970), En torno al sentido. Ensayos semióticos, Gredos, Madrid 1973.

GreIMAS, Algirdas J.; CouRTÉs, Joseph (1979), Semiótica. Diccionario razonado de la teoría del lenguaje, Gredos, Madrid 1982.

Himanen, Pekka (2002), La ética del hacker y el espíritu de la era de la información, Barcelona, Destino.

LeJEUNE, Philippe (1975), El pacto autobiográfico y otros estudios, Megazul-Endymion, Madrid 1994.

LEVY, Steven (1984), Hackers. Heroes of the computer revolution. O'Reilly Media, Sebastopol 2010.

Lotman, Iuri M. (1998), La semiosfera II. Semiótica de la cultura, del texto, de la conducta y del espacio, Cátedra, Madrid.

LozANo, Jorge, ed., (2014), Secretos en red. Intervenciones semióticas en el tiempo presente, Sequitur, Madrid.

12 Para estudiar las relaciones entre máscara y retrato véanse las estimulantes reflexiones de Louis Marin (1983 y 1983-1984). Una opinión contraria a esta relación la encontramos en Starobinski 1970. Starobinski considera que un relato autobiográfico no es un retrato en el sentido de que no contiene ni duración ni movimiento. 
LozAno, Jorge; DíAz, Susana, eds., (2013), Vigilados. WikiLeaks o las nuevas fronteras de la información, Biblioteca Nueva, Madrid.

MARIN, Louis (1983), "Masque et portrait : sur la signification d'une image et son illustration au XVIIe siècle", en Image et signification. Rencontres de l'École du Louvre, La Documentation française, Paris, pp. 163-180.

-(1983-1984), "Masque et portrait", Pictura/Edelweiss n 3, "La Véronique, le voile, le suaire", Toulouse, pp. 88-96.

- (1999), L'ecriture de soi, PUF, Paris 2015.

Morin, Edgar (1962), El espíritu del tiempo, Taurus, Madrid 1966.

RoJek, Chris (2001), Celebrity, Reaktion Books, London.

StAROBInSKI, Jean (1970), "Le style de l'autobiographie" en La relation critique, Gallimard, Paris, pp. 83-98.

Sterling, Bruce (1992), The Hacker Crackdown: Law and Disorder on the Electronic Frontier, Bantam Books, New York.

\title{
RESUMEN
}

La relación que un determinado sujeto mantiene con lo que los códigos de una cultura consideran como "conducta correcta" está en el origen de la obtención de un derecho a la biografía que, por un lado, establece diferentes tipologías culturales como la del héroe o el bandido, y por otro, permite al sujeto entrar a formar parte de una determinada memoria cultural. El artículo pretende abordar una definición de la figura Julian Assange, bautizado como el icono de la revolución mundial en ciernes, abordando las condiciones que le harían ser merecedor de una biografía. Para ello, se prestará atención a la sanción que se ha tratado de depositar sobre él en diversas manifestaciones textuales y se abordará el problema en torno a la autoría que planteó la publicación de su Autobiografía no autorizada.

Palabras clave: Julian Assange, Autobiografía, icono.

\section{The Julian Assange Affair: the Right to an Unauthorised Autobiography}

\begin{abstract}
The relationship that a particular individual has with what the codes of a culture considers "right conduct" is at the origin of obtaining a right to a biography, which, on the one hand, establishes different cultural types like the hero or bandit, and secondly, allows the subject to become part of a particular cultural memory. The article aims to give a definition of the figure of Julian Assange, dubbed the icon of aworld revolution in the making, addressing the conditions that would be worthy of his biography. To this end, we pay attention to the sanction that has tried to place him in various textual representations textual and this should be analysed regarding the authorship problem raised with the unauthorized publication of his autobiography.
\end{abstract}

Keywords: Julian Assange, Autobiography, icon.

\section{RÉSUMÉ}

La relation qu'un individu entretient avec les codes d'une culture, considérée comme " bonne conduite » est à l'origine de l'obtention d'un droit à la biographie, d'une part, que établit différents types culturels comme le héros ou bandit, et d'autre part, permet au sujet de devenir partie d'une mémoire culturelle particulière . L'article vise à répondre à une définition de la figure de Julian Assange, surnommé l'icône de la révolution mondiale en cours, et aborde les conditions qui seraient dignes de sa biographie . À cette fin, on prêt attention à la sanction qui a été essayée de placer sur lui dans diverses manifestations textuelles et cela devrait être adressée au sujet des problemes sûr l'auteur que a soulevé la publication non autorisée de son autobiographie.

Mots-clé: Julian Assange. Autobiographie. icône. 